\title{
Simulation Prediction of Crashworthiness Feature of Advanced Composites
}

\author{
Wen-Ming $\mathrm{ZHAO}^{\mathrm{a}_{\star}}$, Xiao-Su $\mathrm{YI}^{\mathrm{b}}$ \\ Beijing Institute of Aeronautical Materials, AVIC, Beijing, 100095, China.

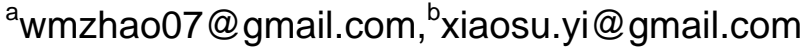 \\ ${ }^{*}$ Corresponding author: Wen-Ming Zhao
}

Keywords: Energy absorption, Metal-composite hybrid structure, Specific energy absorption

\begin{abstract}
Based on the research of crashworthiness of advanced composites, PAM-Crash simulation software was utilized to predict the crash behavior of thermoset matrix and thermoplastic matrix. The simulation results demonstrated that the thermoset matrix and thermoplastic matrix showed an ideal fragment collapse mode, with a SEA of $63.3 \mathrm{~kJ} / \mathrm{kg}$ and $50.9 \mathrm{~kJ} / \mathrm{kg}$, respectively. Both the SEA values are higher than Aluminum alloy, $17.32 \mathrm{~kJ} / \mathrm{kg}$, which means both material systems are promising to replace metal as energy absorption structure in transport applications.
\end{abstract}

\section{Introduction}

The chief concern for crashworthy structure design is to absorb maximum energy within the limited space available, while keeping the peak loads transmitted to occupants to a minimum. Thus the ideal force-displacement curve would have a rectangular shape, as shown in Fig. 1. To approach such behavior with brittle composite structures requires the establishment of a controlled crushing mode of failure, with a localized "crush-front", rather than instability-dominated failure caused by buckling. This is in contrast to metallic energy-absorbing structures, which absorb energy by plastic deformation and folding.

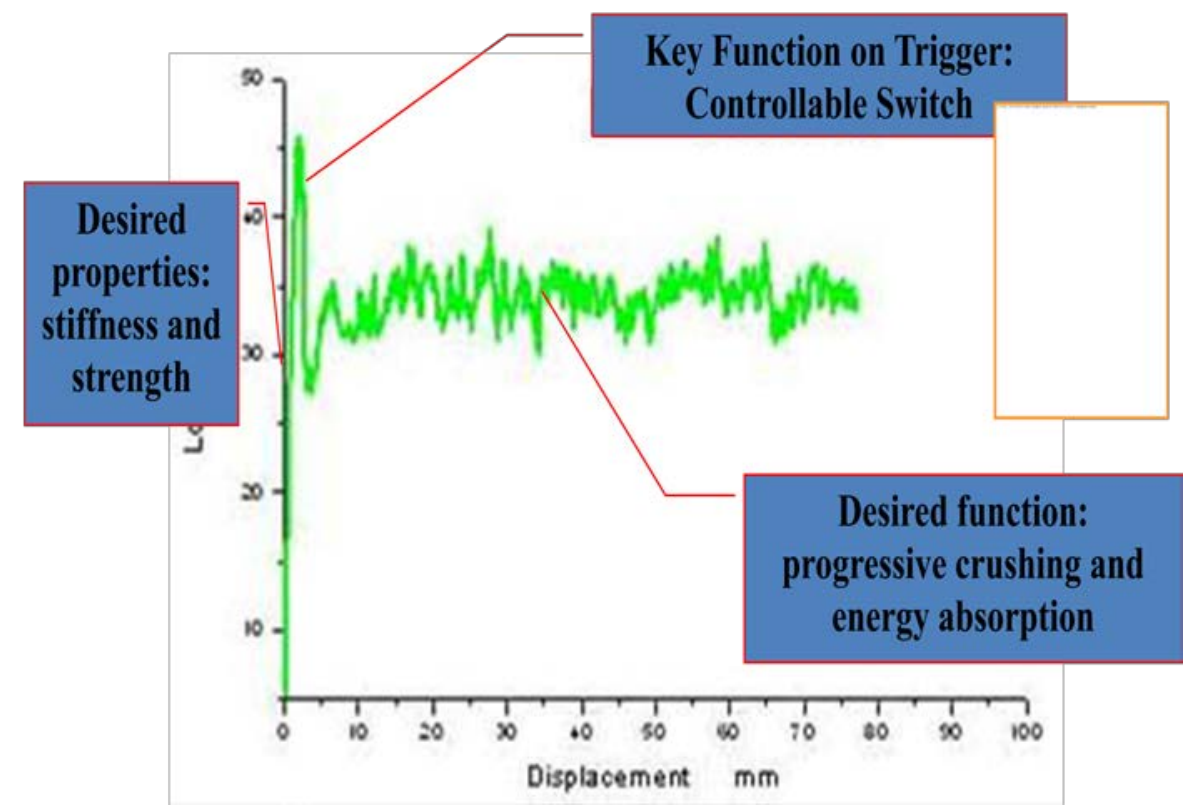

Fig. 1. Typical force-displacement curve of composite crash element.

The research of crash-energy absorption of composite materials and structures began around 1976 . Thornton et al. reported the excellent energy absorbing capability of fiber reinforced composites [1, 2] and gave very useful experimental data such as the influences of fiber orientation, fiber architecture, trigger mechanism, experiment constraints et al [3-8]. Experimental results showed that tubes made of glass fiber and carbon fiber has much more specific energy absorption than that made of Kevlar fiber. Carbon and glass reinforcing composites failed in longitudinal delaminates and brittle fracture 
mode, whereas Kevlar reinforcing composites often failed in Eular buckling mode. Generally, carbon fiber/epoxy composites have the highest energy absorption capabilities than others. In recent years, metal/composite hybrid structures have been studied and different results were obtained [9]. PAM-CRASH is powerful commercial software to simulate the dynamic crash procedure of energy absorbing structures.

\section{Model Set Up}

\section{Reference Frame and Units}

According to the space limitation, the maximum crash displacement cannot longer than $110 \mathrm{~mm}$, the typical impact velocity is $16 \mathrm{~km} / \mathrm{h}$, and the peak impact force should be lower than $110 \mathrm{kN}$. For composite crash box, the outer dimensions should be $150 \mathrm{mmx} 65 \mathrm{mmx} 285 \mathrm{~mm}$. Based on this industrial requirement, experimental and simulation work has been done by BIAM [10]. And the SEA value of $\mathrm{Al}$ alloy (2024-T3) is $17.32 \mathrm{~kJ} / \mathrm{kg}$, the maximum displacement is $116 \mathrm{~mm}$, and the weight of the box is $1.02 \mathrm{~kg}$.

\section{Model Assumption}

Using the experimental observations as a guide, a damage mechanism - based failure model was developed to predict the energy absorption characteristics of the composite tubes. The model consists of two main parts: the material module, which describes the mechanical behavior of the composite; and the tube crushing model, which describes the generous behavior of the tube as it is being crushed.

\section{Load Condition}

To verify the material model of the software, $120 \mathrm{~kg}$ rigid drop weight at a velocity of $6 \mathrm{~m} / \mathrm{s}$ was chosen here. Otherwise, the rigid drop weight is $1000 \mathrm{~kg}$ and the drop velocity is $4.44 \mathrm{~m} / \mathrm{s}$ for crash box.

\section{Contact Definition}

Contact is the mathematics model during the drop weight affect with the tube. Here, Contact Type 33 was used to define the contact, where drop weight is the slave and crash absorber is the master, as shown in the following. During the crash process, large deformation happened in the structure and the mass of crash box itself impact each other, which was defined as self-contact (Contact Type 36). A self-contact algorithm prevented the elements of the box from passing through each other, and also provided friction between the different parts of the structure.

\section{Composites Manufacturing and Modeling}

\section{Composite Tube Specimen Fabrication [11]}

The composite tubes were made using T300 carbon fiber and BIAM made epoxy 5288 resin as the thermosetting composite matrix, and AS4/PPS as the thermoplastic composites. The mechanical properties of T300 and AS4 are similar, while thermosetting resin matrix is much higher than the PPS, although PPS has been proved to have good processibility. The basic properties of the fiber and resin matrix, as well as T300/5288 and AS4/PPS composite are showing in Table 1 and Table 2, where the fiber volume fracture is $55 \%$.

The circular cross-section tubes were fabricated using a solid metal mandrel. Composite materials in the form of prepregs were wrapped around the mandrel. The laminate sequence is [+45/-45/0/0/90/0]s and nominal cured ply thickness of the tape prepreg was $0.125 \mathrm{~mm}$. The assembly was then placed vertically in an autoclave for curing. After the tube was processed, it was removed from the oven and the mandrel extracted. Individual tube specimens were machined from the long tube. Typically, the tubes were machined to lengths of $100 \mathrm{~mm}$ and one end was chamfered at a $45^{\circ}$. The chamfer was incorporated for all composite specimens to limit the initial failure load and initiate the crushing process. 
Table 1 Fiber and matrix material mechanical properties

\begin{tabular}{|l|l|l|l|l|}
\hline Materials & Modulus & Elongation & Strength & Density \\
\hline & $\mathrm{MPa}$ & $\%$ & $\mathrm{MPa}$ & $\mathrm{cm}^{2}$ \\
\hline T300 & 230 & 1.8 & 4210 & 1.78 \\
\hline AS4 & 231 & 1.87 & 4278 & 1.80 \\
\hline 5288 & 3.5 & 4.3 & 98 & 1.26 \\
\hline PPS & 3.3 & 4.0 & 84 & 1.43 \\
\hline
\end{tabular}

Table 2 Mechanical properties of T300/5288 and AS4/PPS

\begin{tabular}{|l|l|l|}
\hline Mechanical Properties & T300/5288 & AS4/PPS \\
\hline Longitude tensile modulus, GPa & 145 & 114 \\
Longitude compression modulus, GPa & 117 & 128 \\
Longitude tensile strength, MPa & 1670 & 1840 \\
Longitude compression strength, MPa & 1260 & 1002 \\
Poisson ratio & 0.317 & 0.334 \\
\hline Transverse modulus, GPa & 9.0 & 8.8 \\
Transverse tensile strength, MPa & 69.4 & 49 \\
Transverse compression strength, MPa & 214 & -- \\
\hline Interlaminate shear strength, MPa & 94.0 & 75 \\
\hline Shear strength, MPa & 118 & 103 \\
Shear modulus, GPa & 4.82 & 4.8 \\
\hline
\end{tabular}

\section{Test Equipment and Procedures}

The drop testing was carried out with an impact velocity of $6 \mathrm{~m} / \mathrm{s}$ and the impact energy of $2000 \mathrm{~J}$. T300/5288 tubes crushed exhibited in a mixed mode of fragmentation and splaying, which was clearly shown in the microstructure failed zone, as shown in Fig.2. The crushed tubes show observe several fracture and collapse mechanisms: fibre fracture, bundle buckling, matrix cracking, fibre-matrix debonding, delamination and a variety of shear related mechanisms. The resulting force-displacement curve demonstrated the expected uniformly and progressively process (Fig. 3). Here, the specific energy absorption (SEA) is $70.82 \mathrm{~kJ} / \mathrm{kg}$.
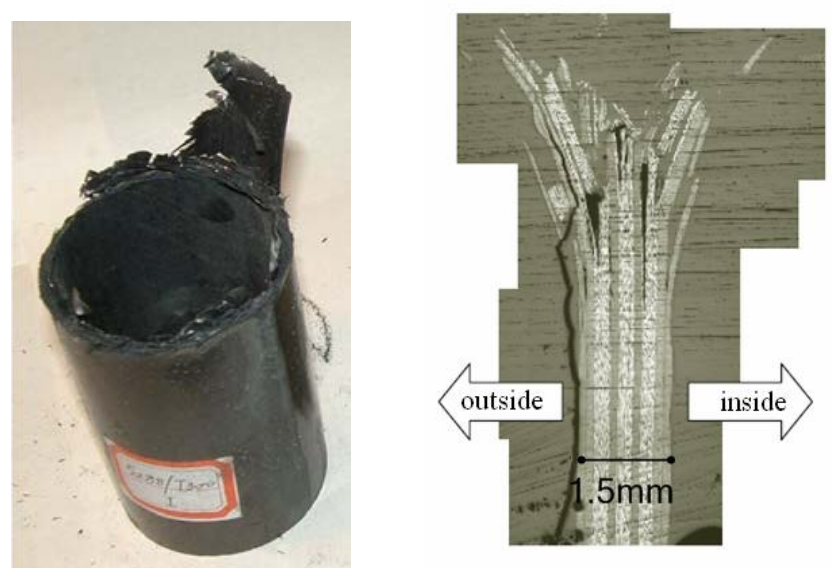

Fig. 2 Drop test onto a T300/5288 tube and the microstructure of the specimen. 


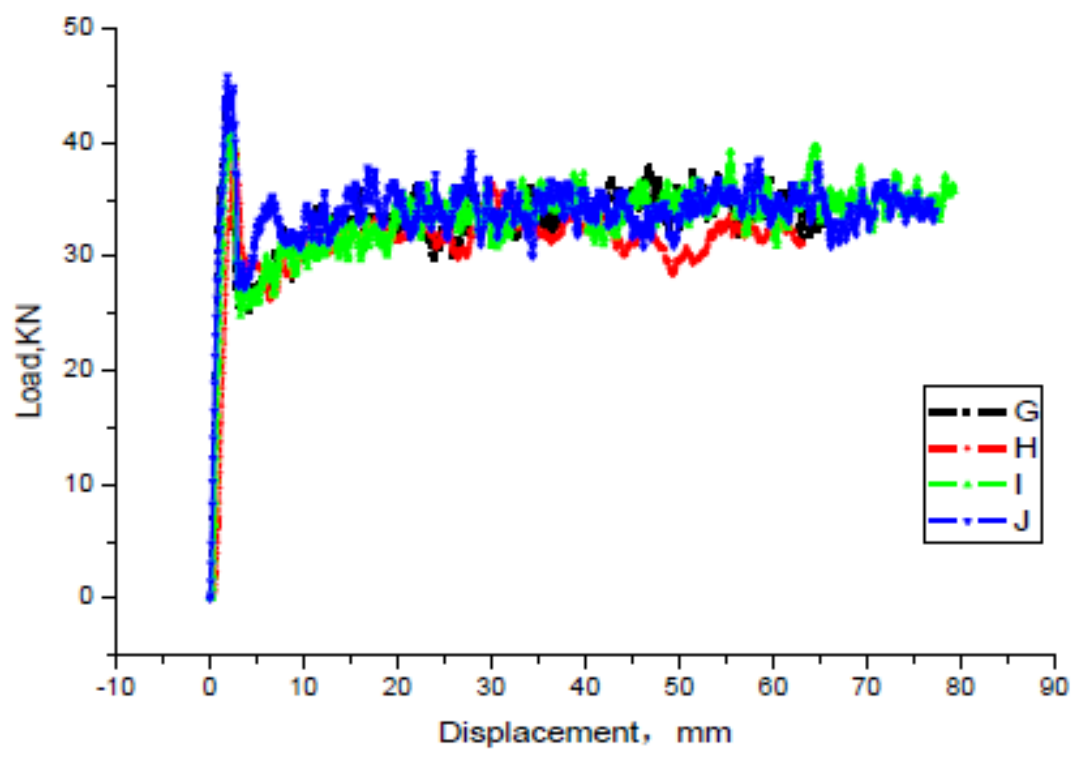

Fig. 3 The load-displacement result of crash process.

Thermosetting composites, T300/5288, crashed in fragments in a uniform, progressive way. The plies lay-up sequence is [ $+45 /-45 / 0 / 0 / 90 / 0]$ s and the trigger angle is $45^{\circ}$. The specific energy absorption is $70.82 \mathrm{~kJ} / \mathrm{kg}$ when under a drop weight of $120 \mathrm{~kg}$ at $6 \mathrm{~m} / \mathrm{s}$ impact velocity.

\section{Calibration of Composite Model}

The performance of the proposed model should be evaluated by comparing the model predictions to experimental data. Here, thermosetting composite tubes, T300/5288, were taken as the calibration reference, and the tube parameters are shown in Table 3. Material 131 of PAM-CRASH was used to simulate the composite structure. There are 12 plies in the circular tube and one plate of shell mesh in each ply. The adjacent layers are connected with bonding element; and also the bonding element could simulate the interlayer strength, because the bonding element has the capable of presenting strength and fracture properties. At the same time, contact pair was taken to avoid penetrating each other and also could simulate the interlayer fabrication effect. And the monolayer failure criterion is PUCK 2000, where GIC $_{\text {and }}$ GIC values were used for the laminate failure criterion.

Table 3. Composite model of T300/5288 tube.

\begin{tabular}{|l|l|}
\hline Materials & T300/5288 \\
\hline Shells & 144000 \\
\hline Plies layup sequence & $(45 /-45 / 0 / 0 / 90 / 0)$ s \\
\hline Single ply thickness/mm & 0.125 \\
\hline Wall thickness/mm & 1.5 \\
\hline Trigger angle $^{\circ}$ & 45 \\
\hline
\end{tabular}

The maximum displacement is $69.5 \mathrm{~mm}$ at $22.4 \mathrm{~ms}$. The total energy absorption is $2160 \mathrm{~J}$, and the SEA is $71.7 \mathrm{~kJ} / \mathrm{kg}$. Good agreements with the experimental results were obtained, as shown in Table 4. Under around impact energy of $2160 \mathrm{~J}$, the SEA is $71.7 \mathrm{~kJ} / \mathrm{kg}$, which is in a good agreement with the experimental test result, as shown in Table 4. Thus, the composite model set up, including the bonding definition, contact, loading condition, is well confirmed.

Table 4. Comparison of experimental and simulation results.

\begin{tabular}{|l|l|l|l|l|}
\hline Results & Time & Displacement & Energy & SEA \\
\hline & $\mathrm{ms}$ & $\mathrm{mm}$ & $\mathrm{J}$ & $\mathrm{kJ} / \mathrm{kg}$ \\
\hline Experimental & 23 & 72 & 2000 & 70.82 \\
\hline Simulation & 22.4 & 69.5 & 2160 & 71.7 \\
\hline
\end{tabular}




\section{Design and Simulation of T300/5288 and AS4/PPS Crash Box}

Here, the material card was still the same and there are 28 plies in this conical tube and one plate of shell mesh for each ply. This mode was applied to thermoset composite, T300/5288, first. Considering the recycling feature as well as the automatic mass production in the future, thermoplastic composite structure, AS4/PPS, was carried on based on the model of thermoset composite. Table 5 showed the materials parameters and the geometries shown in Fig. 4.

Table 5. Composite model of T300/5288 \& AS4/PPS.

\begin{tabular}{|l|l|l|}
\hline Materials & T300/5288 & AS4/PPS \\
\hline Shells & 131712 & \\
\hline Laminate layup sequence & {$[0 / 0 / 45 /-45 / 0 / 0 / 90 / 0 / 0 / 90 / 0 / 0 /-45 / 45 /] \mathrm{s}$} \\
\hline Mono ply thickness/mm & 0.125 & \\
\hline Wall thickness $/ \mathrm{mm}$ & 3.5 & \\
\hline Trigger angle ${ }^{\circ}$ & 45 & $1.60 \times 10^{\circ}$ \\
\hline Density $/ \mathrm{kg} / \mathrm{m}^{\circ}$ & $1.57 \times 10^{\circ}$ & 0.435 \\
\hline Weight $/ \mathrm{kg}$ & 0.425 & \\
\hline
\end{tabular}
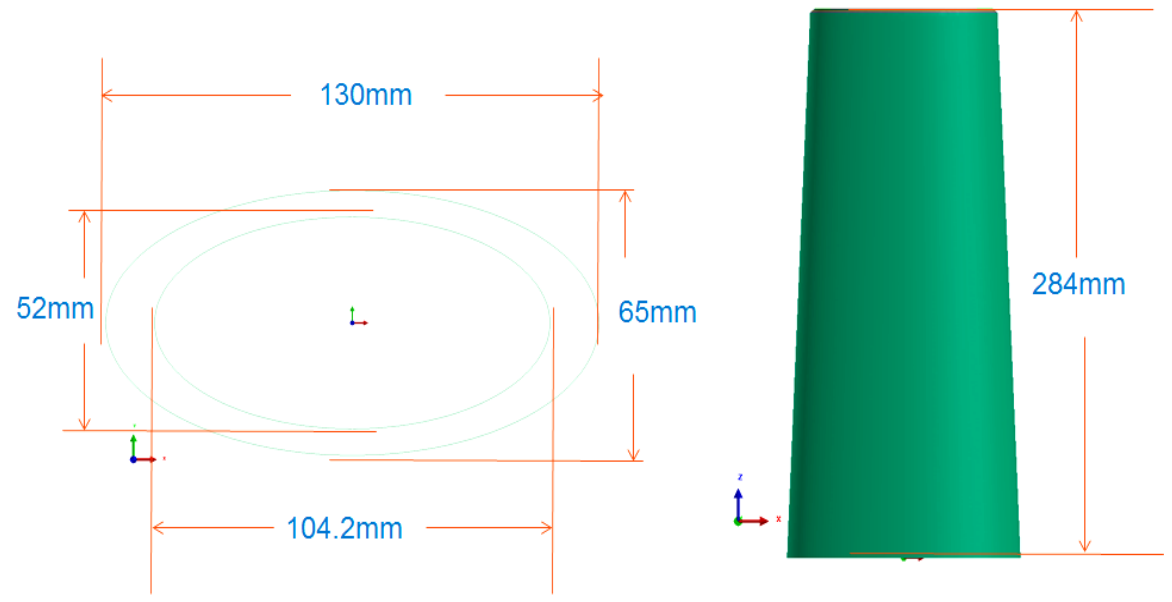

Fig.4 Final elliptical cross-section geometry model of crash box.

Drop weight procedure is an instant process, and the period is normally very short. For T300/5288 thermoset material, the maximum crushing distance was $112.5 \mathrm{~mm}$ at $48.8 \mathrm{~ms}$ and the total energy absorbed is $2160 \mathrm{~J}$ and SEA is $63.3 \mathrm{~kJ} / \mathrm{kg}$, shown in Fig5 (a) . For AS4/PPS thermoplastic material, the maximum crush distance was $135 \mathrm{~mm}$ at $47 \mathrm{~ms}$, and the SEA was $50.9 \mathrm{~kJ} / \mathrm{kg}$. The crash fragments are shown in Fig.6.
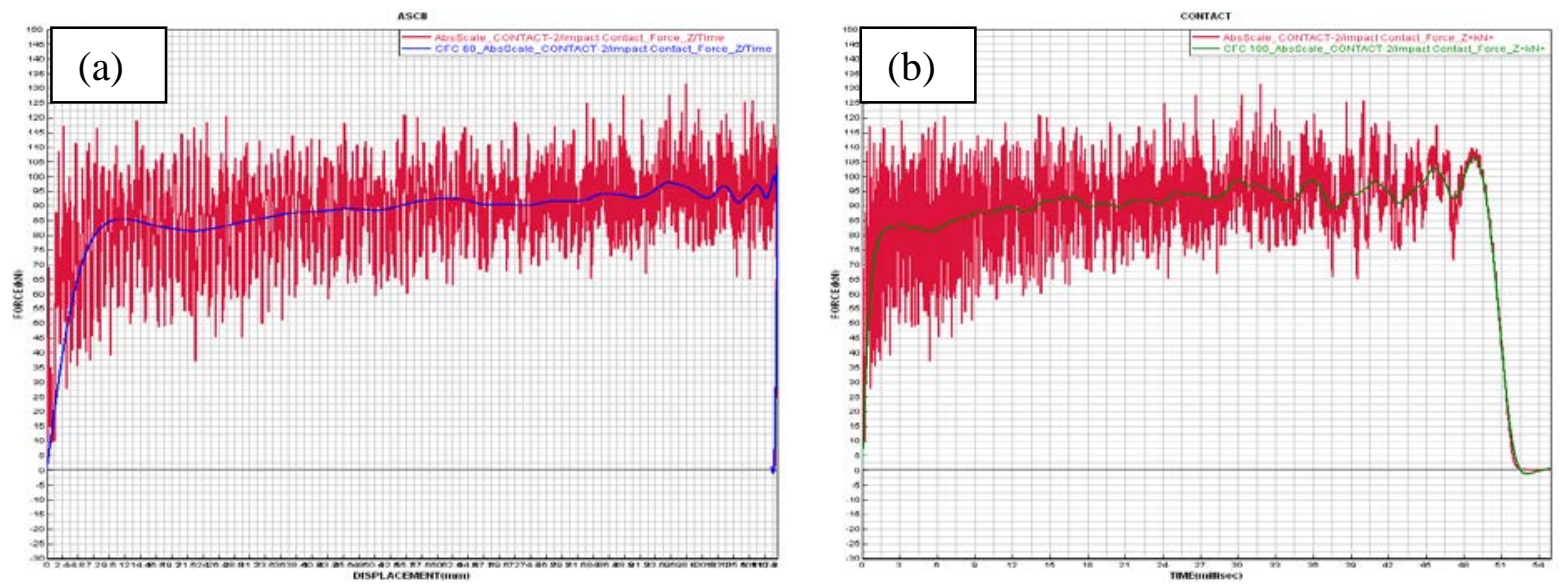

Fig. 5 Force vs displacement response for (a)T300/5288 and (b) AS4/PPS. 

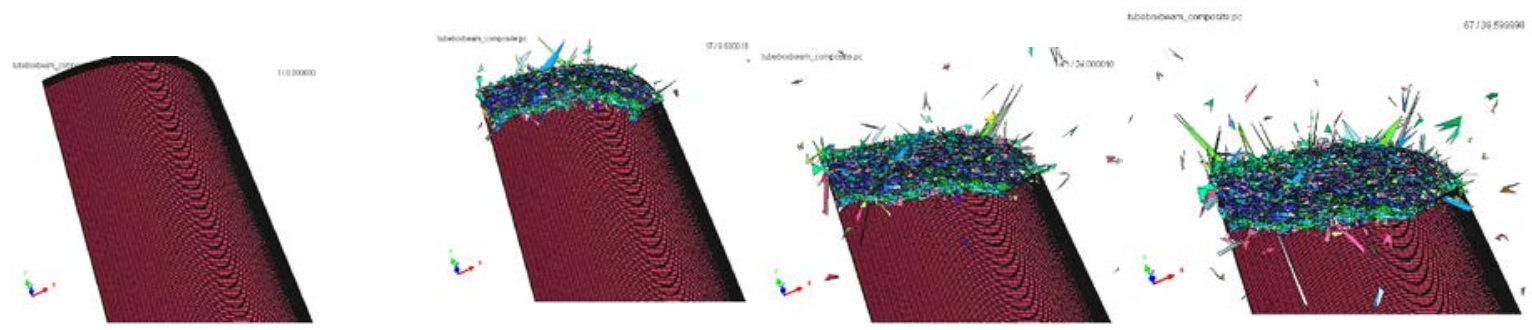

Fig. 6 Development of failures in FEM simulation of AS4/PPS.

\section{Summary}

The simulation work was carried out based on experimental work, and the well matched result demonstrated the model parameters were well set up. Both thermosetting composites and thermoplastic composites can meet the requirement of certain specific application.

1) For thermosetting composite, T300/5288, the maximum crash displacement is $112.5 \mathrm{~mm}$, and SEA is $63.3 \mathrm{~kJ} / \mathrm{kg}$.

2) For thermoplastic composite, AS4/PPS, the maximum crash displacement is $135 \mathrm{~mm}$, and SEA is $50.9 \mathrm{~kJ} / \mathrm{kg}$.

\section{Acknowledgement}

This research was financially supported by the Daimler AG.

\section{Reference}

[1] P. H. Thornton, Energy absorption in composite structures, Journal of Composite Materials, 13(1979): 247-262.

[2] P. H. Thornton, \& P. J. Edwards, Energy absorption in composite tubes, Journal of Composite Materials, 16(1982): 521-545.

[3] G. L. Farley, Energy Absorption of Composite Materials, Journal of Composite Materials, 17(1983): 267-279.

[4] G.L. Farley, Energy absorption of composite material and structures. In: Proceedings of the 43rd American Helicopter Society Annual Forum. St. Louis, USA. 1987, pp. 613-627.

[5] G. L. Farley, Effect of Fiber and Matrix on the Energy Absorption of Composite Materials, Journal of Composite Materials, 20(1986):322-334.

[6] G. L. Farley, The Role of Fiber and Matrix in Crash Energy Absorption of Composite Materials, Journal of the American Helicopter Society, 1986, p:52-58.

[7] C. H. Chiu, Effects of Braiding Parameters on Energy Absorption Capability of Triaxially Braided Composite Tubes, Journal of Composite Materials, 32(1997):1964-1983.

[8] H. Hamada, Effect of Fiber Orientation on the Energy Absorption Capability of Carbon Fiber/PEEK Composite Tubes, Journal of Composite Materials, 30(1996): 947-963.

[9] M. R. Bambach, Thin-Walled Structures, 48(2010): 440-452.

[10] W.M. Zhao, A FRP light-weight concept of crash box absorber, Industrial Project report, BIAM. (2012)

[11] Y.G. Chen, The Crashworthiness of Composite Tubes, PhD thesis, BIAM. (2004) 